\title{
Fascismo hoy, ¿̨realidad concreta o treta opositora? El caso colombiano
}

Fascism today, concrete reality or oppositional trick? The Colombian case

\author{
Luis Carlos Castro Riaño \\ Universidad Nacional de La Plata (UNLP), Argentina \\ https://orcid.org/0000-0002-4033-5089
}

Ensayo

Fecha de recepción: 23 de enero de 2019

Fecha de aceptación: 8 de abril de 2019

\section{Para citar este artículo}

Castro Riaño, L. C. (2019). Fascismo hoy, ¿̇ealidad concreta o treta opositora? El caso colombiano. Campos en Ciencias Sociales, 7(2), 219-236. DOI: https://doi. org/10.15332/25006681.4970

1 Magíster en Ciencias Sociales, estudiante de doctorado en la Universidad Nacional de La Plata (UNLP). Correo electrónico: lucacas2010@hotmail.com 


\title{
Resumen
}

En nuestros días, en Latinoamérica, decir que toda tendencia política de carácter conservador o neoliberal es "fascista" se ha convertido en una práctica que desborda el sentido común y es denunciada en medios de información cuya posición ideológica es contraria a aquellas. En Colombia, por ejemplo, el "uribismo" es el objeto de este señalamiento. Con el fin de establecer una certidumbre al respecto, en el siguiente ensayo se exponen los rasgos del fascismo a la luz de su epistemología y se comparan con algunas acciones sociopolíticas de las gestiones administrativas que inspiran ese apelativo en dicho país.

Palabras clave: Estado, política, establecimiento, uribismo, totalitarismo.

\begin{abstract}
In our days, in Latin America, to say that any political tendency of a conservative or neoliberal nature is "fascist" has become a practice that goes beyond common sense and is denounced in media whose ideological position is contrary to those. In Colombia, for example, "uribismo" is the object of this signaling. In order to establish a certainty in this respect in the following essay there are exposed the features of fascism in the light of its epistemology, and these are compared with some socio-political actions of the administrative procedures that inspire that name in that country.
\end{abstract}

Keywords: State, politics, establishment, uribism, totalitarianism. 


\section{INTRODUCCIÓN}

El término "fascio", cuya raíz es italiana, alude a un conjunto de varas -puestas unas sobre otras- atadas por su centro con un hacha engastada en uno de sus extremos. Durante el siglo XX, en Europa, este elemento fue empleado por varios grupos sociales como símbolo de lucha: los revolucionarios lo implementaron para promover la solidaridad y la adición de militantes comprometidos con su causa; los campesinos para revelarse contra los terratenientes, y el nacionalismo de izquierda para contagiar el fervor de sus campańas y sumar simpatizantes. En el siglo XX, terminada la Primera Guerra Mundial, en la península itálica, Benito Mussolini lo empleó para expresar la disposición de un grupo compuesto por exsoldados, nacionalistas, revolucionarios y sindicalistas, para perseguir y eliminar al socialismo por oponerse al nacionalismo. La organización se llamó "Fasci di Combatimento Italiano". Su doctrina, el "fascismo", se convirtió en un movimiento político de masas que irrumpió en la historia mundial, en Italia, el 23 de marzo de 1919, como un acto de violencia contra toda tendencia socialista y a la vez contra la legalidad burguesa, en nombre del interés nacional superior (Paxton, 2005). Este fenómeno, que posteriormente se replicó en el nazismo y el falangismo, terminó por representar el hecho político más repudiado del siglo pasado y el determinante de muchas de las injusticias sociales que se cometieron en ese período.

Los marxistas fueron sus primeras víctimas. Desde antes que Mussolini lo desarrollase en su máxima expresión, lo definían como "el instrumento de la alta burguesía para combatir al proletariado cuando los medios legales disponibles del Estado resultaban insuficientes para someterlo" (Paxton, 2005, p. 15) Luego, en el apogeo del fenómeno, precisaron una definición antifascista que a la larga representó su ortodoxia y se difundió entre los principios básicos de la tercera internacional: "dictadura terrorista y descarada de los elementos más reaccionarios patrioteros e imperialistas del capital financiero" (Paxton, 2005, p. 16).

Con el pasar de los años se han propuesto diferentes interpretaciones y definiciones en torno a las singularidades de este fenómeno político, pero no se ha logrado establecer un consenso universal ni una explicación satisfactoria de sus lógicas. Se ha señalado que su esencia es el totalitarismo (Woolf, 1974), en tanto no deja ningún aspecto 
de la conducta humana libre de la definición y control del Estado, e incluso se lo ha llegado a apreciar como un tipo de ideología con un núcleo mítico que presenta varios cambios (Paxton, 2005). El uso conceptual, así mismo, ha sido diverso: en algunos casos se convirtió en una sinécdoque para denominar movimientos totalitarios diferentes, en otros fue consagrado como el mecanismo para designar las acciones de la derecha que esgrimen u ostentan autoridad; y en la gran mayoría se redujo a alguien que está en contra de aquello que se considera es bueno para la "gente de a pie".

En consecuencia, su empleo se ha hecho frecuente -las más de las veces de manera acrítica e instrumental- para referirse, peyorativamente, a personajes de la política cuya inclinación es literalmente "conservadora" o "neoliberal". Esta correlación, que generalmente adquiere su forma en la acción de una corriente opositora, más allá de que sea legítima o no, por una parte dificulta la identificación de los actos propiamente fascistas y de su naturaleza, en tanto práctica política concreta. Por otra parte, tergiversa la realidad y entorpece la explicación de los factores que la sustentan, por ejemplo: a) las circunstancias que posibilitan el acceso permanente de los mismos grupos al control del Estado; b) la reseña de esos grupos; c) los mecanismos de coacción que utilizan para conformar su capital electoral y, d) los intereses específicos que los mueven. En cualquier caso, se alimenta una idea fatalista respecto de la inalterabilidad del sistema político, se entrañan odios inculcados, se polariza la sociedad y por lo tanto se atrofia, cuando no se anula, la ejecución de acciones efectivas encaminadas a subvertir su funcionamiento.

En la actualidad varios medios de comunicación latinoamericanos vienen advirtiendo sobre su presencia en algunos Estados de la región, calificando a sus presidentes y sus gestiones como "fascistas"; entre ellos se encuentran Mauricio Macri de Argentina, Sebastián Piñera de Chile, Mario Abdo Benítez de Paraguay, Jair Bolsonaro de Brasil (Gentili, 2018) e Iván Duque de Colombia. En esta última república, en lo que va del siglo XXI, el "uribismo", una fuerza política que reúne tanto a liberales como a conservadores, nucleada hoy en el partido Centro Democrático y amalgamada en la cúpula del ejecutivo, no ha dejado de recibir ese apreciativo por parte de actores políticos, de académicos y, desde luego, del sector que -preso de la espontaneidadsuele reproducir ciegamente los enunciados de unos y otros: el pueblo. 
Recientemente en la revista $C E P A$ (Centro Estratégico de Pensamiento Alternativo) ${ }^{2}$, edición número 27 , en el editorial, que a propósito se titula "el fascismo social y la nueva derecha”, se mencionan una serie de acciones de las últimas tres administraciones -Uribe, Santos, Duque-, y se afirma que en el trasfondo se dibuja "la emergencia del fascismo social, cultural y tecnológico" (CEPA, 2018, p. 4). Del primero señala que se basa en el "clasismo", lo que "significa aplastar a los que son considerados inferiores y a todos aquellos que son o piensan distinto" (p. 4); del segundo afirma que proviene del "traqueteo", exalta el éxito más allá del mérito, y tiene entre sus "ídolos a Pablo Escobar (...) al igual que a aquellos que encarnan el arribismo y la criminalidad, incluyendo a políticos, deportistas y estrellas de la farándula” (p. 5); el último lo aduce del "culto a los artefactos más avanzados" para imponer su voluntad y controlar a la sociedad en su totalidad.

En el texto se define al fascismo escasamente como "el culto a la muerte y a la violencia para imponer el capitalismo" y se indica que se ha impuesto "enmascarado con la falacia de una democracia parlamentaria de tipo liberal, una división de poderes, libertad de prensa, pluralismo y tolerancia... con todo lo cual se camufla la desigualdad, la injusticia y la miseria” (p. 5). Así la situación, no está de más revisar la especificidad del fenómeno y comprobar si efectivamente el uribismo es un movimiento político fascista, o solo es denominado de ese modo por sus opositores.

Con el interés de avanzar en esa dirección a continuación se hace un breve repaso de las especificidades del fascismo. En él se siguen los aportes de varios referentes epistémicos, transitando de los rasgos generales a los particulares y viceversa, mientras se comparan, en simultáneo, con algunas acciones políticas que han sido noticia en medios de información reconocidos y que han tenido lugar desde la administración estatal iniciada en el país en 2002. El ejercicio tiene dos fines: i) esclarecer las particularidades del fenómeno $y$, ii) establecer si efectivamente la sociedad colombiana padece ese siniestro en la actualidad.

2. Revista de pensamiento crítico y alternativo que, como reza su descripción: "coadyuva a la reconstrucción de la nación colombiana desde sus raíces económicas, históricas, sociales, políticas, culturales, étnicas y ambientales”. 


\section{Rasgos generales}

El fascismo tiene muchas formas, de hecho sus componentes son peculiares al bonapartismo así como a las dictaduras totalitarias modernas, y puede existir tanto en una monarquía como en una república (Poulantzas, 1971). Abordado en términos de ideología -es decir, de doctrina política que busca imponer una idea completa y universal acerca de la naturaleza del hombre y de la sociedad, pero que además concluye en un programa de acción política- plantea principios éticos así como parámetros de organización y conducta individual que tienen por fin el control profundo de la vida política y el disciplinamiento de la sociedad (Pérez, 1997). Tiende a girar en torno de la persona de un dictador o líder militar, alrededor del cual se desarrollan prácticas de lealtad, mística y unidad. Este adquiere su fortaleza con el apoyo de otros individuos que se agrupan en su favor y aprueban sus acciones, por ejemplo integrantes de grupos económicos, magistrados o funcionarios de la fuerza pública (Paxton, 2005).

El régimen administrativo actual de la República de Colombia se diferencia porque no posee un líder de origen castrense, pero es similar al siniestro en tanto cuenta con una figura central que, además de encarnar valor, unidad y entrega, se las ha arreglado para continuar al frente de su dirección, seleccionando sustitutos maleables y diseñando toda una estructura política, con el aval de funcionarios políticos, de militares y de grupos de poder como empresarios o banqueros.

Quienes promueven la práctica del fascismo se interesan por aspectos como la centralización del poder, al igual que de los puntos clave de la vida política y económica y la eliminación de las formas de oposición ideológica (Woolf, 1974). Crean una estructura corporativa de organizaciones para perseguir a los que se declaran en su contra (Pérez, 1997), mantienen contacto paternalista permanente con el pueblo pero nunca recomiendan la abolición de la propiedad privada de los medios de producción y tienden a prohibir las huelgas (Woolf, 1974).

El uribismo, además de dirigir el ejecutivo y de poseer la mayoría de curules del legislativo, ha manifestado su interés por centralizar el control del Estado en varias oportunidades. En los primeros meses de la gestión actual este interés se expresa en 
el proyecto de reforma política a la justicia, el cual entre otros aspectos le otorga al presidente de la república el derecho a elegir de forma directa al Fiscal General de la Nación (revista Semana, 13 de septiembre de 2018). El modelo económico que ha implementado se ha basado en la concentración de tierras en pocos propietarios, en el extractivismo, en la concesión de derechos de explotación del subsuelo a multinacionales y en la reducción de impuestos a los grandes capitales, consolidando así su monopolio y la supremacía de los sectores que lo siguen. La estructura que lo sostiene implementa diferentes artefactos para prolongar su hegemonía, son de destacar uno bélico y otro político: por una parte la conformación de un aparato paramilitar que, entre otros delitos, propende elecciones y reelecciones haciendo uso de la violencia armada (Calderón, 2018); por otra el trabajo mancomunado con partidos evangelistas para asegurar el voto de creyentes incautos (Calderón y Gómez, 2018).

La corriente uribista ha expresado el paternalismo de diversas formas en nombre de los intereses generales de la nación, bien sea persiguiendo objetivos políticos en pro de la "seguridad democrática", tomando decisiones arbitrarias a título de instituciones como la familia o asistiendo a consejos comunitarios en zonas inhóspitas del país, generando la impresión de asumir la atención personal de sus problemáticas. El derecho a la huelga ha sido blanco de sus ataques y cercenado en diferentes oportunidades; a la fecha es objeto de debate y desde el Ministerio de Defensa se afirma que está manipulada por grupos al margen de la ley que buscan desestabilizar la legitimidad del Gobierno (El Espectador, 14 de septiembre de 2018).

El fascismo tiende a suponer que las necesidades sociales se agotan con una economía de mercado en donde la fuerza de producción asume el gasto público (Pérez, 1997). El uribismo no se queda atrás. Este rasgo lo expresa, sobremanera, con sus tratados comerciales internacionales e incluso cuando intenta liberar de impuestos al empresariado nacional; todo lo cual está manifiesto en sus leyes de financiamiento (revista Semana, 22 de diciembre de 2018).

En la evolución del fascismo se han identificado cinco etapas (Paxton, 2005) evidentes en el uribismo a lo largo de su trayectoria: 1) creación de un movimiento, que en el caso analizado se llamó "primero Colombia” y posteriormente fue transformado 
en un movimiento ciudadano; 2) arraigo en el sistema político, hecho que aquí se acompañó con la conformación del Partido de la U; 3) consagración en el poder, instancia que se confirmó con la primera reelección "democrática” del país, y con los dos mandatos sucesores; 4) ejercicio del poder, derecho que se ha autootorgado a lo largo de más de 15 años, alterando para ese fin la Constitución Política Nacional y, 5) radicalización o entropía, cosa que ha logrado resignificando las fronteras entre lo público y lo privado, estigmatizando el ejercicio de la opinión crítica, reconfigurando las relaciones entre el individuo y la colectividad y ampliando los poderes del ejecutivo, pero también liberando emociones agresivas, promoviendo una carrera armamentista y, entre otros aspectos, difundiendo su doctrina mediante métodos de propaganda organizada.

Las generalidades que las dos tendencias comparten son múltiples. En una y otra se expresa la unidad con la que un partido trabaja articulado con elites tradicionales para manipular a las masas y revertir la situación, el atropello de las libertades democráticas y la persecución violenta, redentora y sin limitaciones, éticas o legales, con objetivos de limpieza interna y expansión exterior. En el contexto colombiano estos rasgos se materializan con la coalición de partidos políticos que estableció el uribismo para alcanzar nuevamente el ejecutivo y en la fuerza compuesta por ideologías diferentes que se unen -en torno a enemigos comunes-, por su pasión de regenerar a la nación (conservadores y liberales hoy camuflados en la mayoría de partidos políticos nacionales). Las dos doctrinas también se asemejan en la similitud de sus acciones políticas, en que ambas crean crisis ilusorias, en el dominio de un grupo específico sobre los demás, en sus posiciones hacia posturas e ideologías antagónicas, en la promoción de una integración estrecha en torno a un fin colectivo, en la apología a la eficacia de su voluntad y en su autoatribución respecto al derecho a legislar sin limitaciones de ningún tipo.

Estos rasgos del fascismo provienen, en su mayoría, de análisis empíricos realizados en lugares y contextos diferentes al que lo originó, es decir, de la Italia en tiempos de Mussolini. Por lo tanto, conviene -a propósito de los dos fines que motivan este texto- hacer una aproximación, digamos más precisa, a su manifestación inicial y a sus rasgos característicos concretos. 


\section{Rasgos específicos}

Umberto Eco (1997), en su célebre texto "el fascismo eterno", enumera catorce características específicas del fenómeno, de las que fue testigo, ya que creció, durante su emergencia y auge, entre fascistas y partisanos. Una buena parte ha sido aludida por interesados en el tema y, sin lugar a dudas, equiparable al uribismo. Veamos:

- Culto a la tradición, en nuestro caso de manera obsesiva, a prácticas tradicionalistas, y por lo tanto anacrónicas, que no admiten formas de ordenamiento diferentes a la que ha imperado en el país desde su fundación.

- Rechazo al desarrollo de la razón, lo cual se expresa en el ámbito político y, particularmente, en el abandono del sector educativo. Son ya conocidas las pésimas condiciones de su remuneración social y económica, la baja calidad de la educación que ofrece el Estado, comparada con la de otros países de la región como México, y los escasos recursos asignados a la investigación científica, entre otros factores.

- Culto a la acción por acción, manifiesto por parte del uribismo en el fomento de prácticas que no son efectivas a la solución de problemáticas sociales; por ejemplo la creación de grupos de autodefensas o el uso insistente del glifosato para acabar con los cultivos de coca. Esto último pese a que por años se ha usado con efectos adversos para el medio ambiente -y para la población-, sin lograr reducir la producción del estimulante.

- Desprecio por el pensamiento crítico en tanto percibe el desacuerdo. Esta situación se evidencia, entre otros aspectos, en la criminalización de docentes, en especial de aquellos intelectuales cuyas críticas son contundentes. Se señalo tres casos puntuales, los dos primeros ejemplares de los "falsos positivos judiciales": 1) la persecución y el encarcelamiento de los profesores William Javier Díaz en 2008 y Miguel Ángel Beltrán en 2009, ambos absueltos luego de varios años de presidio; 2) la acusación, del propio Álvaro Uribe, según la cual los escritos del docente investigador Mauricio Archila, integrante del 
Cinep y de la Comisión de la Verdad "son calumniosos y apologistas del terrorismo" (revista Semana, 11 de octubre de 2017).

- Persecución a la diversidad. Se trata de la estigmatización y miedo por la pluralidad. En el uribismo ello se expresa, por ejemplo, cuando se cataloga el pensamiento feminista como ideología de género o cuando abiertamente sus miembros promueven conductas homofóbicas en las personas: caso Ordoñez, quien no tuvo ningún inconveniente en expresar sus aversiones mientras ocupó el cargo de Procurador General de la Nación.

- Apelación a la frustración de los sectores sociales en algún tipo de riesgo. El uribismo supo canalizar la crisis de representación política y el descontento social que el país vivía a principios de siglo para fundamentar su discurso y llegar al poder bajo la promesa del cambio y la erradicación militar de la subversión armada. En la última campaña presidencial, ante los procesos de paz y el repliegue de las Fuerzas Armadas Revolucionarias de Colombia, recurrió a la difusión de falsas noticias acerca del contexto venezolano y alimentó el temor de la llegada del "castrochavismo" al territorio colombiano utilizando la figura del candidato de la oposición (Fernández, 2017).

- Nacionalismo y xenofobia. Estos son dos postulados uribistas desde su advenimiento. El primero, manifiesto en el discurso y la acción patriótica -la guerra que el uribismo le declaró al terrorismo de hecho fue en nombre de la madre patria-. El segundo, instaurando pánico colectivo y difundiendo información manipulada, por ejemplo con la idea de la crisis migratoria venezolana y el efecto que ocasiona al orden nacional (revista Semana, 2 de octubre de 2018).

- La guerra como principio permanente. La lucha contra el terrorismo ha sido un principio del régimen uribista que además le ha valido la negación del conflicto interno, la fortificación de su aparataje bélico, la justificación de cientos de operativos militares y la autorización del montaje de siete bases militares estadounidenses a lo largo y ancho del país. 
- Elitismo. Manifiesto aquí en el origen social así como en la escasa experiencia y formación de quienes ocupan los altos cargos del Estado a los que se llega por elecciones. Ejemplo: presidente de la república, presidente del Senado o jefes de departamento y embajadores.

- Apología al heroísmo, principio que el uribismo ha promovido de manera enfática. Por ejemplo bajo la etiqueta de "los héroes en Colombia sí existen", que no alimenta más que la simpatía por la fuerza opresora del Estado; otro referente es la importancia que concede a la entrega de condecoraciones a quienes se destacan por su servicio a la nación, caso Cruz de Boyacá; y la conmoción que genera alrededor de aquellos que pierden la vida en el ejercicio de sus labores militares.

- El líder se presenta como la voluntad común del pueblo. El uribismo suele hacerlo abiertamente en nombre de todos los colombianos, por cierto, en su discurso se expresan y comunican decisiones a título del bienestar nacional, inclusive por encima de la normatividad constitucional. La política de defensa y seguridad democrática, tras de la cual se cometieron actos criminales como los "falsos positivos", representa una evidencia fidedigna del asunto.

Hasta aquí no parece exagerado decir que el uribismo, y por lo mismo la política del Centro Democrático, es fascista. Eco (1997) reconoció otras aristas, además de las anteriores, que asoman en esta tendencia: la exaltación al Estado, a la religión y a sus símbolos; la censura religiosa sobre lo sexual combinada con un patriarcalismo machista en el que participan las mujeres que idolatran al macho; la apelación a la violencia como la salida más efectiva de erradicar todo lo nocivo para la nación y al armamentismo como técnica para lograr ese fin; la denuncia de todo lo que es considerado corrupción; la propaganda, y la manipulación mediática.

Sin embargo, existen rasgos del fascismo que no reproduce el uribismo y que también es preciso aludir, en desmedro de las emocionalidades políticas. Tres hacen parte de las catorce señaladas por el filósofo citado: una especie de autohumillación por la riqueza y la fuerza del enemigo, la voluntad del poder propia del género masculino y 
el empleo de un lenguaje pobre. Si algo ha hecho el Estado y el sector que lo dirige es mostrarse fuerte ante la opinión pública y el mundo; el uribismo ha sabido integrar mujeres entre su bancada y su discurso no es rico pero tampoco escueto, por lo menos no en la figura de su máximo referente.

El fascismo tiene características concretas que no se deben soslayar porque son precisamente las que lo materializan como fenómeno político. Es antiliberal, anticonservador y racista (Paxton, 2005), el uribismo, por el contrario promueve esas corrientes ideológicas. Además, los fascistas no alcanzaron el poder por la condición privilegiada de un grupo de personas, mientras que es este uno de los factores que garantiza el ascenso al poder y la hegemonía del uribismo. Otro aspecto fundamental del primero es el unipartidismo y, en consecuencia, el "establecimiento de la doctrina de la unidad monolítica” (Woolf, 1974). Dentro de esta lógica el fascismo establece una jerarquía extrema y tiene como última meta la creación de un nuevo ser humano, "el nuevo fascista". El uribismo, a diferencia, es un sector individualista y acaparador, no pretende la unificación de la sociedad, solo la garantía y perpetuación de sus dominios.

Si bien tanto en el uno como en el otro existe la predisposición a la acción violenta contra el socialismo, en Colombia no se puede hablar del desarrollo amplio de esta tendencia, ni antes ni en la actualidad, y no hay que olvidar que previamente a su llegada al poder los fascistas organizaron cruentos enfrentamientos contra los comunistas, conformando escuadras de combate callejero (situación que tiene más similitud a la vivida en el territorio nacional en los arreboles de los cincuenta, durante la violencia bipartidista). Otro rasgo diferencial es que mientras que el fascismo en su inicio se declaró anticapitalista y antiburgués, el uribismo se ha mostrado promotor, sobremanera, de esas disposiciones. También que uno fomenta el Estado social, el otro una república asistencialista; y que mientras que en el primero se abandonan las libertades democráticas, en el segundo es la apología a la democracia la que refuerza su consolidación.

Tampoco se debe pasar por alto que el fascismo surge en contextos de revolución, tiene como base a la pequeña burguesía, suprime la prensa libre, desmantela sindicatos, confina disidentes al ostracismo, hace del poder legislativo una ficción 
y promulga las nuevas leyes directamente desde el ejecutivo sin ninguna forma de oposición. Hechos que no ocurren en Colombia, por lo menos no en la actualidad.

\section{REFLEXIONES FINALES}

Con todo, el fascismo es un fenómeno sociopolítico que trasciende en la cultura. Un modelo administrativo perverso que intenta dar respuestas de tipo disciplinario a problemas de eficiencia y de identidad. Sus rasgos son múltiples, una cantidad considerable se manifiesta de forma tangible en el caso expuesto. El citado número de la revista CEPA (2018) coincide con los que señala aunque no con las lógicas que les atribuye. Se destacan: el carácter represivo y militar del régimen, el asesinato de líderes sociales y populares, la conformación de bandas paraestatales, el culto a la acción por la acción -que ilustra advirtiendo sobre el reinicio de bombardeos con glifosato-, el desprecio por un sector específico -en este caso por "las comunidades campesinas, indígenas y afrodescendientes, las cuales son consideradas como narcotraficantes que hay que combatir a sangre y fuego" (p. 4)-, el uso de los medios de comunicación y el odio a la diferencia ideológica y sexual.

Los aportes epistémicos también revelan varios rasgos que reproduce el uribismo, por ejemplo actúa de forma carismática, glorifica el terror y la violencia, pretende la centralización del poder político, criminaliza la protesta, controla sectores clave de la vida económica, no suprime la propiedad privada, no adopta una nueva Constitución sino que modifica la existente, militariza las ciudades, libera emociones agresivas y se apoya en sentimientos populares.

Sin embargo, estrictamente hablando, el uno difiere del otro. El régimen colombiano se parece en la forma y en la acción pero es sustancialmente distinto a lo que fue el fascismo en sí mismo en su manifestación original, pues no reúne sus componentes fundamentales: no es unipartidista, no es antiliberal, no genera un equivalente nacionalista del socialismo, no manifiesta un racismo tangible en el sentido amplio de la palabra, no elimina toda forma de oposición política, no prohíbe partidos y sindicatos, no encarna una escoria nacional, no confisca propiedades a extranjeros - 
por el contrario se las facilita-, no tiene una base de masas de militancia nacionalista, no abandona las libertades democráticas -las enarbola - y no suprime la prensa libre.

Umberto Eco (1997) afirmaba que el concepto se adapta para todo porque es posible eliminar una o más características de ese régimen y siempre se podrá reconocer como tal. De acuerdo con él: "basta con que una de ellas se presente para coagular una nebulosa fascista” (p. 48). No obstante, cuando se insiste en que el uribismo -o cualquier otro régimen capitalista- es una expresión fiel del fascismo o del neofascismo, se obtura de forma mecanicista la naturaleza concreta del fenómeno y se invisibiliza la trama social que resguarda su legitimidad en el poder. No se puede equiparar, por ejemplo, la conformación de grupos paramilitares en el uribismo con la aparición de las bandas paraestatales conformadas por "il duce". El hecho en uno y otro contexto responde a diferentes situaciones, agentes y momentos históricos. En el caso colombiano con seguridad es efecto, entre otros factores, de la voluntad oligárquica y de la evolución histórica de la violencia que ella ha generado; en el italiano fue la respuesta a la crisis política provocada por el auge del comunismo. Otro tanto pasa con el clasismo y con la exclusión política de sectores sociales a los que se les considera inferiores; este es un rasgo presente desde la fundación del propio Estado colombiano, expresado en la clasificación socioeconómica de su pueblo (ciudadanos y no ciudadanos) y en las constituciones anteriores a la vigente.

Nicos Poulantzas (un referente obligado en el estudio de este tema, que señalaba su latencia en los años setenta), afirma que este fenómeno político resulta de una coyuntura específica de la "lucha de clases" haciendo especial énfasis en que no se puede hablar del mismo sin aludir a la "clase obrera", y mucho menos de esta última sin tratar las políticas del "Komintern"; elementos que no existen en nuestro contexto. Además indica que es una forma específica del "Estado de excepción", advierte que en ningún caso habría que confundirlo con otras expresiones de Estado capitalista y sugiere considerar varios factores para analizarlo en profundidad; por ejemplo, el imperialismo, las dinámicas de surgimiento, el estadio del desarrollo capitalista en el que tiene lugar, la función de los organismos privados como la Iglesia o la escuela y el rol de los aparatos ideológicos (Poulantzas, 1971). Por otra parte el fascismo, a diferencia del uribismo, hizo su emergencia en medio de la creación, desde abajo, de un movimiento de masas, en un contexto de descomposición del 
Estado e inminente peligro de revolución y obtuvo el poder por medio de la violencia organizando escuadras de combate callejero (camisas negras).

Sus rasgos generales son expresión de una praxis política organizada, que también tuvo lugar en Europa, y que se conoce como totalitarismo en tanto tiende a ser absoluta y no sujeta a controles. El régimen colombiano se asimila más a sus tendencias "nazista” y "estalinista” (Arendt, 2004) en la medida en que difunde una ideología, impone el terror y hace uso de una metodología que busca alcanzar el control de la sociedad mediante el empleo de la agitación y la propaganda. Todo ello implementando los mecanismos de coacción en un trabajo articulado con las instituciones del Estado.

Cuando se insiste de manera obstinada en connotar al uribismo de fascismo se pone en evidencia un problema de fondo, clásico de la oposición colombiana y de la izquierda en general, que es necesario que supere si pretende provocar acciones emancipadoras efectivas que conlleven, verdaderamente, al bienestar colectivo. A saber: su incapacidad para asimilar objetivamente la realidad concreta y elaborar conceptos explicativos -propios- que develen las urdimbres organizativas del establecimiento y, en consecuencia, lo subviertan.

Analizar el modus operandi del uribismo requiere un esfuerzo mayor que el realizado aquí para advertir que no se trata de un régimen enteramente fascio. Entre tanto, y si se insiste en introducir los arquetipos de Occidente para explicarlo, es más prudente afirmar que la sociedad colombiana padece una especie de totalitarismo periférico -por su lugar de reproducción pero sobre todo por las lógicas que lo permean bajo esa determinación- producto del arraigo global del imperialismo, matizado del neoliberalismo de ultranza, del capitalismo a lo largo de los últimos 60 años y de la administración de un sector social que ha gobernado históricamente para suplir sus excesos.

Esta breve reflexión nos permite establecer varias certidumbres sobre el fascismo en sí mismo, no así la que se relaciona con la treta de su interpretación, ni aquí ni en los demás países latinoamericanos donde existen Gobiernos etiquetados de ese modo -podemos estar simplemente frente a percepciones espontáneas cargadas 
de emocionalidad ideológica-, así que la pregunta del título que abre este escrito se reserva a las deducciones del lector. En todo caso -siempre que se trate de objetividad, más aun de la dinámica política-, es importante observar cada contexto sin olvidar que es necesario efectuar un análisis pormenorizado de los hechos que acompañaron al fenómeno estudiado y de las situaciones concretas en las que, se supone, se ha establecido. Esto no es más que observar con detenimiento los hechos y fijar la mirada con mayor precaución en lo que se hace, que en lo que suele decirse al respecto. En Colombia, además de tomar distancia pasional con el objeto, será primordial prestar atención a la genealogía de los grupos de poder, así como a sus relaciones, sin menospreciar su complejidad ni los intereses en juego y sin perder de vista tanto el devenir histórico del Estado como de las problemáticas estructurales del país.

\section{REFERENCIAS}

Arendt, H. (2004). Los orígenes del totalitarismo. México D. F., México: Santillana Ediciones Generales.

Calderón,J. (2018).El poder dela derecha colombiana. Telesur. Recuperado dehttps:// www.telesurtv.net/opinion/El-poder-de-la-derecha-colombiana-20180113-0041. html

Calderón, J., y Gómez, A. (2018, 4 de febrero). La re-espiritualización de la política. Celag. Recuperado de https://www.celag.org/la-re-espiritualizacion-la-politica/

CEPA. (2018). Neofascismo y resistencia social. CEPA, 13(27), septiembrediciembre, Bogotá D. C., Colombia.

El Espectador. (2018, 14 de septiembre). Protesta social en la mira del Mindefensa. Diario El Espectador. Recuperado de https://www.elespectador.com/noticias/ politica/protesta-social-en-la-mira-del-mindefensa-articulo-812295 
Eco, U. (1997). Cinco escritos morales. Barcelona, Espańa: Editorial Lumen.

Fernández, F. (2017). Castrochavismo en Colombia: fantasma o realidad. Panam Post. Recuperado de https://es.panampost.com/felipe-fernandez/2017/11/29/ castrochavismo-en-colombia/?cn-reloaded $=1$

Gentili, P. (2018). El fascismo nuestro de cada día. Diario El País. Contrapuntos. Recuperado de https://elpais.com/elpais/2018/10/28/ contrapuntos/1540687510_196909.html

Paxton, R. (2005). Anatomía del fascismo. Barcelona, España: Ediciones Península.

Pérez, M. (1997). Los riesgos para la democracia. Fascismo y neofascismo. Madrid, España: Editorial Pablo Iglesias.

Poulantzas, N. (1971). Fascismo y dictadura. La tercera internacional frente al fascismo. México D. F., México: Siglo Veintiuno Editores.

Semana. (2017, 11 de octubre). El reclamo de los profesores de la Universidad Nacional a Álvaro Uribe. Revista Semana. Recuperado de https://www.semana.com/ educacion/articulo/comunidad-academica-rechaza-twitter-de-alvaro-uribe-contramauricio-archila/546806

Semana. (2018, 13 de septiembre). Reforma a la justicia: presidente nombraría fiscal si la Corte no se pone de acuerdo. Revista Semana. Recuperado de https://www.semana. $\mathrm{com} /$ nacion/articulo/las-claves-de-la-reforma-a-la-justicia-de-ivan-duque/582815

Semana. (2018, 2 de octubre). Con el aumento de la migración venezolana también ha crecido la xenofobia. Revista Semana. Recuperado de https://www.semana.com/ nacion/articulo/crisis-en-venezuela-aumento-de-la-xenofobia-en-colombia/556725 


\section{Campos}

Semana. (2018, 22 de diciembre). La ley de financiamiento aprobada: un triunfo amargo. Revista Semana. Recuperado de https://www.semana.com/economia/ articulo/asi-quedo-la-nueva-ley-de-financiamiento-y-estas-son-las-criticas-que-se-leha-hecho/595781

Woolf, S. (1974). La naturaleza del fascismo. Teoría y praxis. México D. F., México: Editorial Grijalbo. 